\title{
PENINGKATAN ATAU PENGENALAN OBAT TRADISIONAL ATAU JAMU BESERTA KHASIATNYA KEPADA SISWA SMP 11 PANGKALANBUN KOTAWARINGIN BARAT
}

\author{
Yogie Irawan ${ }^{1}$ Bramantio Erlangga ${ }^{2}$ Jamilah $^{3}$ \\ ${ }^{123}$ STIKes Borneo Cendekia Medika Pangkalan Bun \\ ${ }^{1}$ Email : masyuduk@gmail.com
}

\begin{abstract}
ABSTRAK
Penggunaan obat tradisional sebagai alternatif pengobatan telah lama dilakukan jauh sebelum ada pelayanan kesehatan formal dengan menggunakan obat-obatan moderen. Namun, negara Indonesia yang terdiri dari banyak pulau yang didiami oleh berbagai suku memungkinkan terjadinya perbedaan dalam pemanfaatan tanaman sebagai obat tradisional. Hal ini disebabkan setiap suku memiliki pengalaman empiris dan kebudayaan yang khas sesuai dengan daerahnya masing-masing. Kehidupan nenek moyang yang menyatu dengan alam menumbuhkan kesadaran bahwa alam adalah penyedia obat bagi dirinya dan masyarakat. Mulai dari sinilah berkembang pengertian obat tradisional. Menurut Departemen Kesehatan Republik Indonesia, obat tradisional merupakan produk yang terbuat dari bahan alam yang jenis dan sifat kandungannya sangat beragam dan secara turun temurun telah digunakan untuk pengobatan berdasarkan pengalaman (Depkes, 2007). Metode yang digunakan dalam kegiatan ini yaitu penyuluhan, tanya jawab dan diskusi. Hasil kegiatan pengabdian pada masyarakat ini dapat disimpulkan baik. Hal ini dibuktikan bahwa siswa/i SMP 11 Pangkalan Bun dapat memahami cara penggunaan obat tradisional serta khasiatnya yang benar, sehingga mengurangi kesalahan pemakaian obat dan memanfaatkan obat tradisional dengan baik dan benar.
\end{abstract}

Kata Kunci : obat tradisional, jamu

\section{IMPROVEMENT OR INTRODUCTION OF TRADITIONAL MEDICINE OR JAMU AND ITS USEFULNESS TO JUNIOR HIGH STUDENTS 11 PANGKALANBUN KOTAWARWANT WEST}

\begin{abstract}
The use of traditional medicine as a treatment alternative has long been done long before there is formal health service by using modern medicines. However, the Indonesian state consisting of many islands inhabited by various tribes allows the difference in the utilization of plants as a traditional medicine. This is because each tribe has empirical and cultural experiences that are distinctive in accordance with their respective regions. The life of the ancestors who fused with nature grew the realization that nature is a provider of drugs for himself and society. Starting from this is the traditional medicine sense develops. According to the Ministry of Health of the Republic of Indonesia, traditional medicine is a product made from natural ingredients that the type and properties of the content are very diverse and hereditary has been used for treatment based on experience (Depkes, 2007). The methods used in this activity are counseling, questioning and discussion. The results of this community devotion can be concluded. It is proven that the students/I SMP 11
\end{abstract}


Pangkalan Bun can understand how to use traditional medicine as well as correct usefulness, thereby reducing the error of drug use and utilizing traditional medicines well and correctly.

Keywords: traditional medicine, herbs

\section{PENDAHULUAN}

Indonesia merupakan negara terbesar ketiga yang mempunyai hutan tropis terluas di dunia dan menduduki peringkat pertama di Asia Pasifik. Hal ini membuat Indonesia kaya akan sumber daya hayati, salah satu diantaranya adalah tanaman yang dapat berkhasiat sebagai obat. Hutan tropis Indonesia merupakan tempat tumbuh bagi 80 persen tanaman obat yang ada di dunia yang terdiri dari 28.000 spesies tanaman, 1000 spesies diantaranya sudah digunakan sebagai tanaman obat.

Penggunaan obat tradisional sebagai alternatif pengobatan telah lama dilakukan jauh sebelum ada pelayanan kesehatan formal dengan menggunakan obat-obatan moderen. Namun, negara Indonesia yang terdiri dari banyak pulau yang didiami oleh berbagai suku memungkinkan terjadinya perbedaan dalam pemanfaatan tanaman sebagai obat tradisional. Hal ini disebabkan setiap suku memiliki pengalaman empiris dan kebudayaan yang khas sesuai dengan daerahnya masing-masing. Kehidupan nenek moyang yang menyatu dengan alam menumbuhkan kesadaran bahwa alam adalah penyedia obat bagi dirinya dan masyarakat. Mulai dari sinilah berkembang pengertian obat tradisional. Menurut Departemen Kesehatan Republik Indonesia, obat tradisional merupakan produk yang terbuat dari bahan alam yang jenis dan sifat kandungannya sangat beragam dan secara turun temurun telah digunakan untuk pengobatan berdasarkan pengalaman (Depkes, 2007).

Obat tradisional juga diterima dengan baik di hampir seluruh negara di dunia, baik negara berkembang maupun negara maju (Oktora, 2006). WHO merekomendasikan penggunaan obat tradisional termasuk herbal dalam pemeliharaan kesehatan masyarakat, pencegahan dan pengobatan penyakit terutama untuk penyakit kronis, degenerative dan kanker. Data statistik WHO 12 menyebutkan negara-negara di Afrika, Asia dan Amerika Latin menggunakan obat tradisional sebagai pelengkap pengobatan primer yang mereka terima. Bahkan di Afrika, sebanyak $80 \%$ dari populasi menggunakan obat tradisional untuk pengobatan primer. Oleh sebab itu, pemberian obat tradisional yang aman dan efektif menjadi faktor penting untuk meningkatkan derajat pelayanan kesehatan secara keseluruhan (WHO, 2003). Berdasarkan hasil survei The National Health Interview Survey (NHIS), pengguna obat tradisional di Amerika Serikat bahkan mencapai 19\% pada tahun 2002 (Gardiner, et al., 2007). Di Indonesia, dari hasil Survei Sosial Ekonomi Nasional (SUSENAS) dapat dilihat bahwa terjadi peningkatan penggunaan obat tradisional dari 19,8\% menjadi 32,8\% selama tahun 1980 sampai dengan 2004 (Menkes RI, 2007).

Di Indonesia obat tradisional masih digunakan secara luas di berbagai lapisan masyarakat, baik itu di pedesaan maupun diperkotaan. 
Penggunaan obat tradisional semakin meningkat dengan kecenderungan gaya hidup kembali ke alam (Katno, et. al., 2004). Kecenderungan ini sangat terlihat dari maraknya produk-produk berbahan herbal yang beredar di pasaran. Disamping itu belum meratanya sarana kesehatan juga mahalnya harga obat dan banyaknya efek samping dari obat moderen menjadi faktor pendorong bagi masyarakat untuk mendayagunakan obat tradisional (Pramono, 2002).

Dalam the 3rd Conference on Traditional Medicine in ASEAN Countries Menteri Kesehatan RI, dr. Endang Rahayu Sedyaningsih, MPH, Dr.PH mengatakan, obat tradisional dapat menjadi bagian penting dari sistem kesehatan formal di negaranegara di dunia, termasuk ASEAN. Di Indonesia untuk memberikan landasan hukum terhadap obat tradisional dikeluarkan Keputusan Menteri Kesehatan RI No.381/Menkes/SK/III/2007 tentang Kebijakan Obat Tradisional Nasional (KOTRANAS). Salah satu tujuan dari keputusan ini adalah agar tersedianya obat tradisional yang terjamin mutu, khasiat dan keamanannya, teruji secara ilmiah dan dimanfaatkan secara luas baik untuk pengobatan sendiri maupun dalam pelayanan formal.

Meskipun pengguna obat tradisional di kalangan masyarakat sudah sangat banyak namun data tentang alasan dan latar belakang pasien memilih menggunakan obat tradisional masih sedikit. Begitu juga data tentang jenis penyakit yang umumnya diobati dengan menggunakan obat tradisional. Hal inilah yang mendorong penulis untuk melakukan penelitian tentang penggunaan obat tradisional serta khasiatnya.

\section{METODE PENELITIAN}

Metode yang digunakan untuk mencapai pemahaman siswa/siswi SMP 11 Pangkalan Bun tentang tema peningkatan dan pengenalan obat tradisional beserta khasiatnya yang baik dan benar.

Maka diperlukan strategi berupa :

1. Penyuluhan peningkatan dan pengenalan obat tradisional beserta dan khasiatnya.

2. Mengadakan tanya jawab tentang peningkatan dan pengenalan obat tradisional beserta dan khasiatnya, serta monitoring dan evaluasi pelaksanaan program.

3. Diskusi, dilakukan untuk menggali persoalan yang berhubungan dengan peningkatan dan pengenalan obat tradisional beserta dan khasiatnya.

\section{HASIL DAN PEMBAHASAN}

Hasil kegiatan pengabdian pada masyarakat ini dapat disimpulkan baik. Hal ini dibuktikan bahwa siswa/i SMP 11 Pangkalan Bun dapat memahami cara penggunaan obat tradisional serta khasiatnya yang benar, sehingga mengurangi kesalahan pemakaian obat dan memanfaatkan obat tradisional dengan baik dan benar.

Ketersediaan tenaga kesehatan yang bermutu dalam jumlah yang memadai sangat penting bagi pembangunan kesehatan di daerah untuk mencapai tujuan pembangunan kesehatan secara lebih baik. Departemen Kesehatan Republik Indonesia (Depkes RI) (2009) menyatakan bahwa tujuan pembangunan sektor kesehatan adalah meningkatkan kesadaran, kemauan dan kemampuan hidup sehat bagi setiap orang supaya terwujud derajat kesehatan masyarakat yang setinggitingginya. Untuk itu, distribusi tenaga kesehatan dan juga pengetahuan 
generasi muda yang memadai dibutuhkan agar masyarakat di daerah dapat mengerti dan menikmati pelayanan kesehatan yang lebih baik dengan akses yang relatif mudah. Dampak positifnya adalah mereka menjadi lebih mungkin hidup di lingkungan masyarakat dengan perilaku yang jauh lebih sehat, selain itu minat geerasi muda terhadap profesi tenaga keseatan semakin meningkat. Terkait pentingnya tenaga kesehatan, salah satu unsur penting yang berperan dalam penyelenggaraan pembangunan kesehatan adalah sumber daya manusia (SDM) kesehatan. Selain itu, dalam SKN 2012, ada tujuh subsistem yang menentukan pencapaian derajat kesehatan secara nasional, yaitu administrasi kesehatan, informasi kesehatan, sumber daya kesehatan, upaya kesehatan, pembiayaan kesehatan, peran serta dan pemberdayaan masyarakat, ilmu pengetahuan dan teknologi kesehatan, dan pengaturan hukum kesehatan. Ini menunjukkan bahwa ketersediaan dan distribusi tenaga kesehatan yang memadai sangat dibutuhkan untuk mencapai tujuan pembangunan kesehatan nasional.

Kegiatan sosialisasi atau penyuluhan pengenalan obat tradisional atau jamu beserta khasiatnya yang benar pada siswa/i SMAN 1 Sukamara merupakan salah satu rangkaian kegiatan pengabdian masyarakat oleh dosen dan mahasiswa farmasi STIKes BCM. Sosialisasi ini diharapkan dapat membantu siswa/i SMAN 1 Sukamara dalam penggunaan obat tradisional serta khasiatnya yang benar.

Diharapkan melalui kegiatan ini siswa/i dapat menjadi lebih perhatian dalam pemanfaatan obat tradisonal dan khasiatnya yang ada di lingkungan keluarganya

masing-masing khususnya.

\section{KESIMPULAN DAN SARAN Kesimpulan \\ Dapat disimpulkan bahwa penyuluhan peningkatan atau pengenalan obat tradisional beserta khasiatnya dapat meningkatkan pengetahuan dan pemahaman siswa/i SMAN 1 Sukamara mengenai pemanfaatannya obat tradisional untuk memelihara kesehatan dan mencegah serta mengobati penyakit terbukti dengan menggunakan metode tanya jawab siswa/i SMAN 1 Sukamara bisa menjawab pertanyaan yang diberikan.}

\section{Saran}

Dengan adanya kegiatan ini seharusnya kita dapat menggunakan obat tradisional dengan baik dan benar sesuai manfaatnya. Serta tetap menjaga kelestarian lingkungan hidup disekitar kita agar tercipta lingkungan hidup yang sehat.

\section{DAFTAR PUSTAKA}

Ismiyana F., Hakim Rahman A., Sujono Azizah

T.,2013.,"Gambaran

Penggunaan Obat Tradisional UntukPengobatan Sendiri

Pada Masyarakat Di Desa Jimus Polanharjo Klaten"., Fakultas Farmasi Universitas Muhammadiyah Surakarta.

Sukandar E Y.,"Trend an Paradigma

Dunia Farmasi,Industri-

Klinik- Teknologi Kesehatan, disampaikan dalam orasi ilmiah Dies Natalis ITB”, http://itb.ac.id/focus/focus file lorasi-ilmiah-dies-45.pdf, diakses desember 2018 pukul 13.30 WIB 
Shinoda E., 2013., Pengembangan

Jamu Sebagai Warisan

Budaya.,

evrinasp.wordpress.com/2013/

09/08/pengembangan-jamu-

sebagai-warisan-budaya

Prof dr Aditama Yoga T.,2014., Jamu

dan Kesehatan., ISBN 978-

602-0936-18-5 